Brit. Heart f., 1967, 29, 96.

\title{
Experience in the Surgical Treatment of Patients with Common Atrio-ventricular Canal
}

\author{
V. I. BOURAKOVSKI, V. A. BUKHARIN, AND F. N. ROMASHOV
}

From the Institute of Cardiovascular Surgery, Academy of Medical Sciences of the U.S.S.R. (Moscow), U.S.S.R.

The problem of surgical treatment for patients with common atrio-ventricular canal cannot be considered as solved, because of difficulties in diagnosis and complications during surgical intervention and in the post-operative period. The cardinal clinical manifestations of this anomaly have been studied and principles of surgical treatment have been worked out (Lillehei et al., 1957; McGoon, DuShane, and Kirklin, 1959; Johansson and Senning, 1959).

In the Soviet Union, investigations are carried out in clinics under N. M. Amosov, A. A. Vishnevski, S. A. Kolesnikov, P. A. Kouprianov, B. V. Petrovski, and others, to overcome the problems connected with diagnosis and surgical treatment of this kind of cardiac defect. (Various works by these authors are listed in the References.)

We have operated on 21 patients with various forms of common atrio-ventricular canal (by the end of 1963, 400 operations for congenital heart disease had been carried out on the open heart under conditions of artificial blood circulation, using hypothermia and deep hypothermia).

\section{ANATOMical Types of THE DefEct}

There were 11 patients with an incomplete form of A-V canal: 8 of them were found to have a combination of primary atrial septal defect with complete splitting of the septal cusp of the mitral valve. The primary atrial septal defect was generally 2.5 to $3 \mathrm{~cm}$. in diameter. One patient had the primary defect combined with splitting of the septal cusp of the tricuspid valve: the site of the split was where the valve was attached to the septum, and the small opening led to the left ventricle. Thus, the patient had a left-to-right shunt of blood in addition to tricuspid regurgitation.

Received July 15, 1965.
Diagrams illustrating the partial form of common atrio-ventricular canal are shown in Fig. 1.

We have observed considerable diversity in the anatomical picture among a further 10 patients, operated on for the complete form of this defect. This has allowed us to classify our patients into the following three groups.

(1) A common A-V canal with clear halves of the septal cusps of the mitral and tricuspid valves, with a large ventricular septal defect, and a primary atrial septal defect (one case). The split undeveloped cusps of the valves hang like a tent over the muscular edge of the large ventricular septal defect (Fig. 2).

(2) A common A-V canal with well-developed ventral and dorsal parts of the septal cusps connected at their lower surface with the edge of the interventricular septum. The edges of both halves of the cusps are not connected, and the ventricular septal defect is a kind of opening, sometimes a rather deep one. Over this opening is the primary atrial septal defect (Fig. 3). This form is the commonest, and we have observed it in 8 patients.

(3) A common A-V canal without any interatrial septum (Fig. 4). This form has been seen in one patient. The disorder in the development of the interventricular septum and the valve apparatus in this case was identical with the changes that took place in cases in the first group.

Sometimes patients having a common A-V canal are found to have stenosis of the pulmonary artery or aorta, a persistent ductus, and other malformations of the heart and cardinal vessels. This was so in 5 patients, who were not analysed in this study.

\section{Hamodynamic Changes in the Defect}

The hæmodynamic disorders of the common atrio-ventricular canal are caused by septal defects 96 


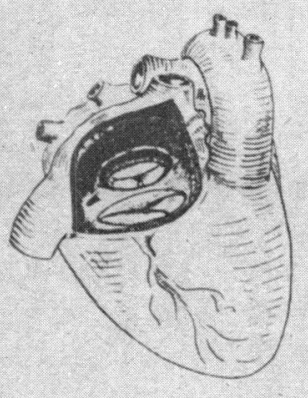

Fig. 1.-Diagrams illustrating the partial form of the common A-V canal. Left, splitting of the mitral cusp. Right, splitting of the medial cusp of the tricuspid valve.
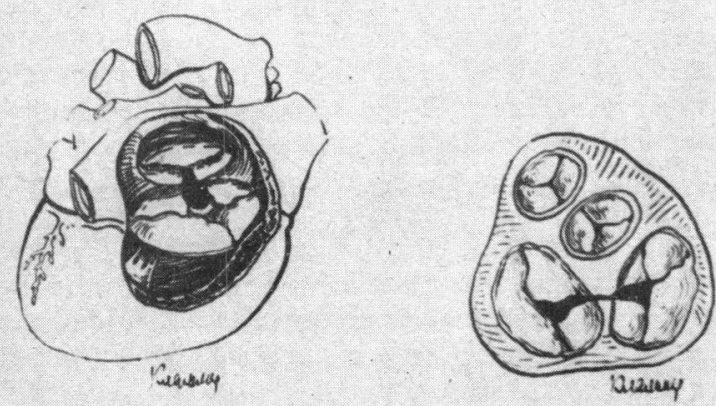

FIG. 3.-The complete form with a small ventricular septal defect.

The splitting of the mitral valve leads to regurgitation of blood into the left atrium, and so to an increase in the left-to-right shunt through the atrial septal defect. In patients with the complete form there is also a simultaneous shunt of blood through the ventricular septal defect. The shunting of a large quantity of arterial blood to the venous side causes, in many cases from the earliest years, severe cardiac dilatation, the appearance of pulmonary hypertension, and insufficiency of blood circulation. The most serious disorders have been observed in patients in the first and third groups, with the complete form of defect. Other patients have similar disorders of circulation but to a lesser degree.

The presence of atrial septal defects and regurgitation through the valves distorts the dynamics of circulation. First, the cycle of atrial work is distorted, and this is reflected in records of atrial and pulmonary capillary pressures; the point " $a$ " is very high in some cases, and at the same time the wave of regurgitation is often difficult to determine.
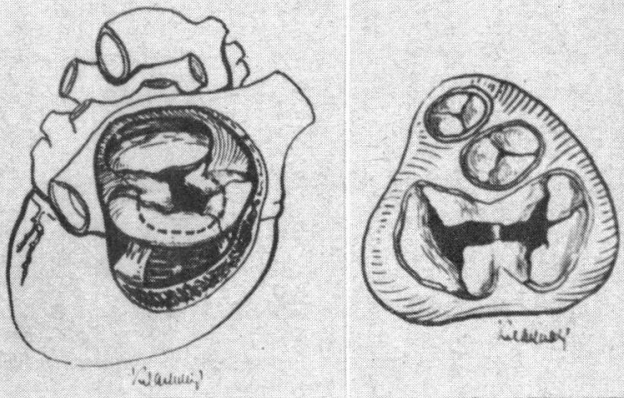

FIG. 2.-The complete form with a large ventricular septal defect.



FIG. 4.-The complete form without any interatrial septum, combined with a large ventricular septal defect.

By analogy with the effect of acquired mitral regurgitation on the recorded curves of pressure in the pulmonary capillaries and left atrium, the presence of regurgitation waves could be expected in cases with the common A-V canal. We have seen this in isolated cases, but generally the wave of regurgitation was not clearly shown or not shown at all. Wakai and Edwards (1956), among others, point out the rarity of such a sign.

The curves of pressure (Fig. 5) recorded in the atria in patients with the complete form of the common A-V canal indicated the regurgitation wave only in the first case (a). In two others (b and c) it was not present. Its rarity can be explained by the complicated anatomical interrelations in cases with common $\mathrm{A}-\mathrm{V}$ canal.

\section{Diagnosis and Clinical Features}

Patients with a common A-V canal represent one of the most serious groups among all those with 


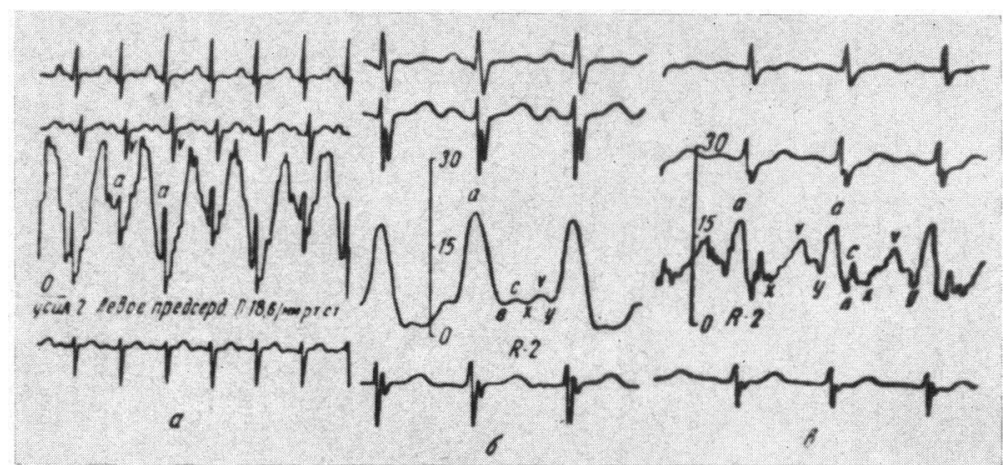

FIG. 5.-Pressure curves in the atria of patients with the complete form of the cardiac defect.

congenital cardiac defects. In the incomplete form the clinical picture is not so serious, though we cannot show an exact parallelism between the nature of the anatomical disorders and the clinical and radiological picture. We have not observed any prevalence in either sex among our patients. The majority were no older than 10 years and only one with the complete form was 15 years old. In almost all, the cardiac defect was diagnosed immediately after birth or in the first months of life, and in two-thirds there were attacks of pneumonia and pulmonary congestion.

All the patients were short of breath. Some children with the complete form had a rapid rate of breathing, up to 40 a minute, even at rest. Owing to the insufficiency of the blood flow to the systemic vessels, children were physically backward and generally inactive. Persistent slight cyanosis of the lips was observed in one patient with the complete form with a large ventricular septal defect. In two others with pulmonary hypertension, slight cyanosis appeared only during physical effort.

A chest deformity, "a cardiac hump", was found in 12 patients. The independent systolic murmur at the cardiac apex, which was caused by the mitral regurgitation, and the second systolic sound in the second left intercostal space were heard in all cases. Its intensity was not usually great, and it was caused by the large volume of blood passing through the pulmonary valve ring. Besides this, in two-thirds of our patients the diastolic murmur was loudest over the xiphisternum, and in 4 over the pulmonary artery. As a rule, the second sound over the pulmonary artery became louder, and in half the patients it was split.

Arterial hypotonia was present in half our patients, and various degrees of liver enlargement were found in two-thirds of them.

Electrocardiographic Examination. This is very important in the diagnosis of common $\mathrm{A}-\mathrm{V}$ canal.
The changes in the cardiogram are caused by mitral regurgitation and the overcharge of the right ventricle and atrium.

The discovery of right bundle-branch block with clearly pronounced overcharge of the right ventricle, the deceleration of excitement of the myocardium of the right ventricle, combined with the overcharge and hypertrophy of the myocardium of the left ventricle, and left axis deviation-all these are typical of the common A-V canal. Right axis deviation was noted only in 2 patients with the incomplete form: both were thought to have slight mitral regurgitation. In general, in patients with the incomplete form, the symptoms of overcharge of the right side of the heart are dominant, though this is not always the case.

Half the patients had prolonged atrio-ventricular conductivity ( $\mathrm{P}-\mathrm{R}$ from 0.20 to $0.24 \mathrm{sec}$.) because of clearly pronounced overcharge of the atria and their dilatation. This prolonged conductivity can also be explained by the anatomical peculiarities of the defect.

$X$-ray Investigations. The serious hæmodynamic disturbances give rise to a typical radiological picture, even in earliest years. The heart is considerably enlarged because of the acute dilatation of all the cardiac chambers (Fig. 6).

Investigation in all three projections allows us to determine the dilatation of both atria, expecially the right, and pronounced enlargement of both ventricles. Functional evidence of mitral regurgitation (yokelike movements of the left atrium and systolic displacement of barium in the œsophagus) was not found in all cases.

The pulmonary trunk and its branches were very dilated and pulsatile because of a large volume combined with the mitral regurgitation. The pulmonary picture was intensified in all cases by the filling of both arterial and venous channels.

It is interesting to note that in 10 cases there were 
also pleural lines-replete lymphatic vessels due to venous stagnation in the pulmonary circulation.

Naturally, the pulmonary picture changes as pulmonary hypertension, due to sclerosis of the pulmonary vessels, develops. The "amputated" sharp dilated pulmonary vessels are clearly seen. In the peripheral sections the impoverishment of the pulmonary picture is shown.

Cardiac catheterization allows us to make a final diagnosis. The data obtained by catheterization of chambers of the heart and vessels are indicated in the Table. In more than half the patients the catheter passed to the left atrium and it was located low over the $A-V$ valves, probably because of the primary atrial septal defect.

Ten patients had not only an increase in the percentage oxygen saturation in the right atrium, but also a similar increase in the right ventricle. We have seen this mainly in patients with the complete form, with the blood shunt at the level of both atria and ventricles.

\section{The Technique of the Operation}

Most patients have been operated on with an artificial circulation through the trans-sternal access, and the right antero-lateral approach has been used only twice.

In 9 patients the operation was performed on the non-contracting heart. In 2 of these, deep common hypothermia $\left(10^{\circ}-12^{\circ} \mathrm{C}\right.$.) was used, with the blood

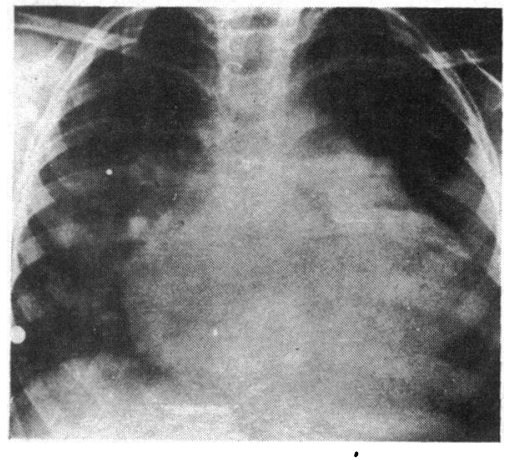

FIG. 6.-Radiograph of patient 4 years old, with the incomplete form of the cardiac defect.

circulation arrested. In 2 others, local hypothermia up to $10^{\circ} \mathrm{C}$. was used, with the aorta blocked (clamped), in 2 others, with cardioplegia, by citrate of potassium, and in 3 , we operated on the fibrillating heart with the coronary blood flow continued with an artificial blood circulation with moderate hypothermia.

In all other cases the correction of the cardiac defect was done on the contracting heart with extracorporeal blood circulation carried out at the normal body temperature of the patient. We conclude that this method is the best for cases having a common atrio-ventricular canal, because during the process of stitching the edges of the defect and tying them it is possible to monitor the electrocardiogram. We had to abandon all the

TABLE

PRESSURE AND OXYGEN SATURATION IN CAVITIES OF HEART AND VESSELS

\begin{tabular}{|c|c|c|c|c|c|c|}
\hline \multirow[t]{3}{*}{ Patient No. } & \multirow{3}{*}{$\begin{array}{l}\text { Age } \\
(\mathrm{yr} .)\end{array}$} & \multicolumn{5}{|c|}{ Data obtained at catheterization } \\
\hline & & \multicolumn{3}{|c|}{ Pressure $(\mathrm{mm} . \mathrm{Hg})$} & \multicolumn{2}{|c|}{$\begin{array}{c}\text { Oxygenation of blood } \\
\text { (percentage) }\end{array}$} \\
\hline & & $\begin{array}{c}\text { Brachial } \\
\text { artery }\end{array}$ & $\begin{array}{c}\text { Right } \\
\text { ventricle }\end{array}$ & $\begin{array}{c}\text { Pulmonary } \\
\text { artery }\end{array}$ & $\begin{array}{l}\text { Superior } \\
\text { vena cava }\end{array}$ & $\underset{\text { artery }}{\text { Pulmonary }}$ \\
\hline $\begin{array}{c}\text { Complete Fo } \\
1 \\
2 \\
3 \\
4 \\
5 \\
6 \\
7 \\
8 \\
9 \\
10 \\
\end{array}$ & $\begin{array}{r}13 \\
10 \\
5 \\
7 \\
7 \\
9 \\
11 \\
15 \\
5 \\
8\end{array}$ & $\begin{array}{r}105 / 60 \\
120 / 75 \\
90 / 54 \\
80 / 50 \\
117 / 87 \\
120 / 90 \\
90 / 80 \\
90 / 70 \\
120 / 90 \\
75 / 50\end{array}$ & $\begin{array}{c}30 / 0 \\
54 / 0 \\
70 / 0 \\
35 / 0 \\
45 / 0 \\
60 / 10 \\
102 / 3 \\
66 / 0 \\
96 / 0 \\
60 / 0\end{array}$ & $\begin{array}{c}29 / 9 \\
60 / 27 \\
33 / 12 \\
60 / 30 \\
87 \\
50 / 25 \\
87 / 45 \\
60 / 30\end{array}$ & $\begin{array}{l}76 \\
70 \\
52 \\
74 \\
75 \\
78 \\
56 \\
77 \\
65 \\
67\end{array}$ & $\begin{array}{l}94 \\
93 \\
87 \\
97 \\
93 \\
87 \\
82 \\
92 \\
81 \\
88\end{array}$ \\
\hline $\begin{array}{c}\text { Incomplete } \\
11 \\
12 \\
13 \\
14 \\
15 \\
16 \\
17 \\
18 \\
19 \\
20 \\
21\end{array}$ & $\begin{array}{r}8 \\
11 \\
4 \\
6 \\
9 \\
7 \\
8 \\
6 \\
14 \\
7 \\
13\end{array}$ & $\begin{array}{r}120 / 84 \\
112 / 75 \\
93 / 68 \\
96 / 66 \\
90 / 60 \\
120 / 70 \\
105770 \\
80 / 55 \\
100 / 55 \\
100 / 30 \\
108 / 72\end{array}$ & $\begin{array}{l}34 / 0 \\
37 / 0 \\
54 / 3 \\
33 / 3 \\
38 / 0 \\
69 / 0 \\
45 / 3 \\
47 / 0 \\
30 / 0 \\
37 / 0 \\
30 / 3\end{array}$ & $\begin{array}{l}34 / 15 \\
30 / 15 \\
54 / 24 \\
30 / 18 \\
36 / 20 \\
45 / 15 \\
44 / 22 \\
30 / 15 \\
22 / 7 \\
30 / 15\end{array}$ & $\begin{array}{l}77 \\
66 \\
69 \\
72 \\
57 \\
82 \\
71 \\
65 \\
66 \\
62\end{array}$ & $\begin{array}{l}94 \\
82 \\
91 \\
86 \\
85 \\
93 \\
87 \\
92 \\
81 \\
77\end{array}$ \\
\hline
\end{tabular}




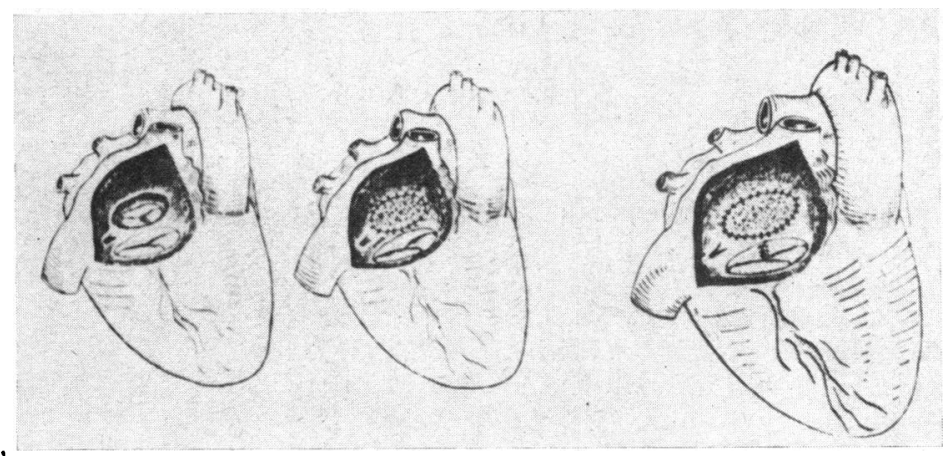

FIG. 7.-Diagram showing the correction of the incomplete form of the defect.

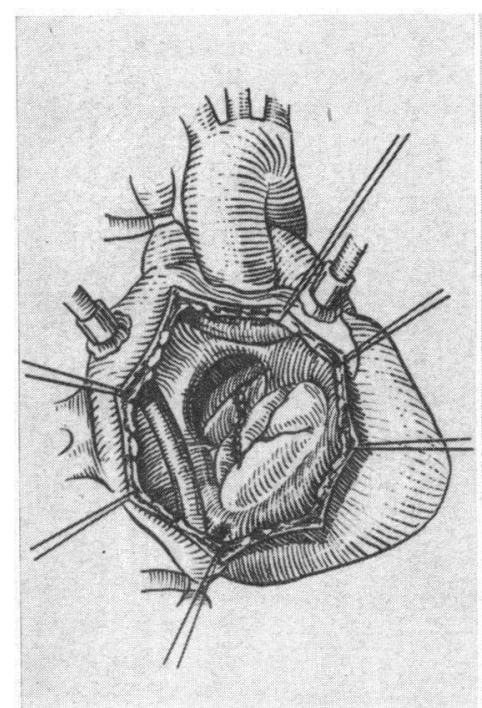

A

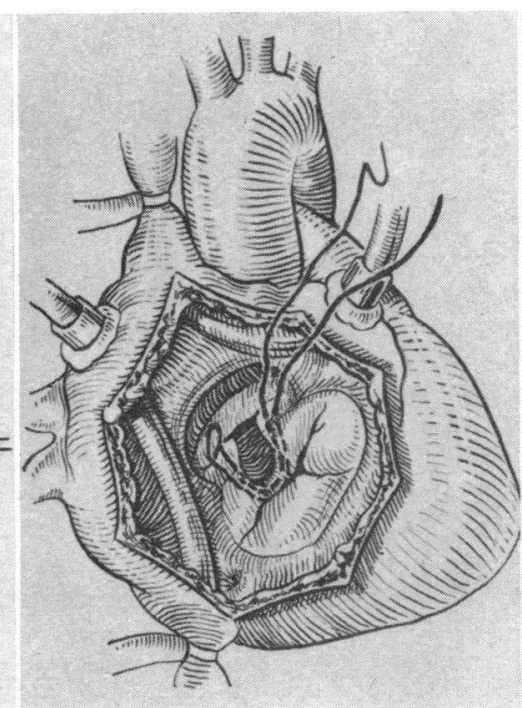

B

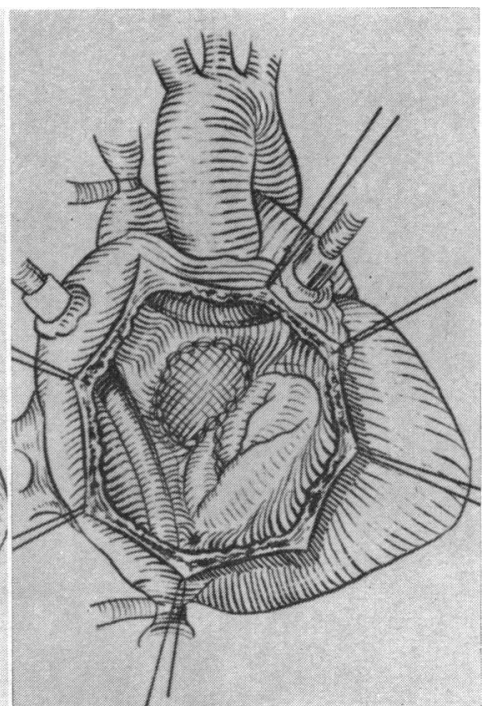

C

FIG. 8.-Operation for the complete form with a small ventricular septal defect (see text).

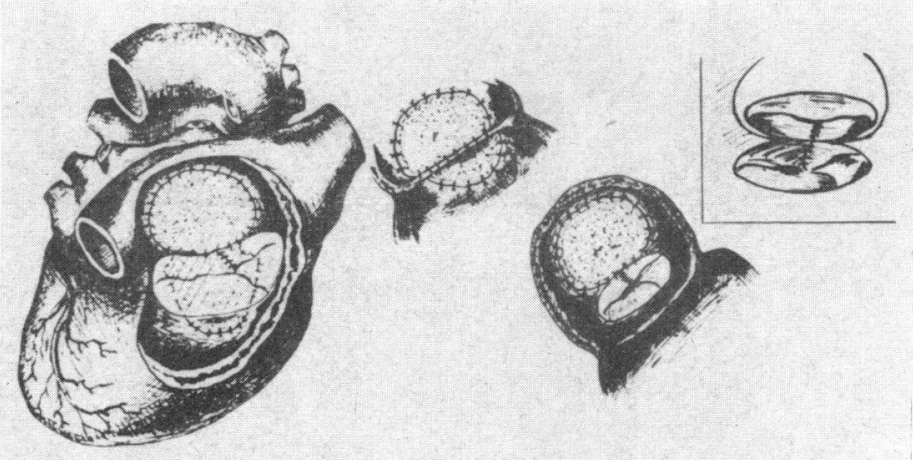

FIG. 9.-Methods for treating the complete form with a large ventricular septal defect. 
methods of cardioplegia, as it was impossible to watch for the moment when complete heart block occurred and also to prevent cardiovascular insufficiency in the period of restoration. One patient, who was operated on using cardioplegia by citrate of potassium, was lost because of this complication. Two patients who were operated on under deep hypothermia died because of the acute cardiac insufficiency. All these patients were suffering from a very serious circulatory disturbance, due to their having the complete form of the common A-V canal. We have observed complete heart block in 4 out of 9 patients: in all these the cardiac defect was closed on the non-contracting heart. On the other hand, only one of 12 patients who had the correction of defect done on the contracting heart had this complication. It should be noted that in one other patient in this group complete heart block developed at the moment when the stitch in the low back part of the defect was tied. After immediate removal of the stitch, normal cardiac contracttions were restored.

For the incomplete form of the defect, correction was carried out by putting in interrupted stitches at the edges of the split valve cusps. We began with the distal edge of the valve and then continued to the interventricular septum. The atrial septal defect was closed with a teflon patch (Fig. 7).

For the complete form of the defect (second anatomical group) the best method of operation is the one proposed by Johansson and Senning (1959) (Fig. 8). Using this method we operated on 6 patients, and 4 recovered. This operation consists in putting a mattress stitch in the thick part of the interventricular septum, in the zone where the defect is. After the stitch is tied, the ventricular septal defect can be closed and the bases of the split cusp can be drawn together. The split of the cusp is dealt with after this by putting in interrupted stitches, and the primary atrial septal defect is closed with a patch.

In the case of the first and third anatomical varieties (Fig. 9) more complicated surgical intervention should be carried out.

\section{RESULTS}

Of 11 patients operated on for the incomplete form of the cardiac defect, only 2 have died (both had the combination of the primary defect with a split cusp of the mitral valve). One girl died when her heart stopped on the third day after the operation, due to cardiac insufficiency. The death of the second child was due to cardiac insufficiency, hypoxia, and secondary hæmorrhage.

Of 10 patients having the complete form of the defect, 6 died. Two, who belonged to the first and third anatomical groups, were suffering from serious pulmonary hypertension, and one of them also had pronounced cardiac insufficiency. Both died from acute cardiac insufficiency (for all of them we used various methods of cardioplegia). One other patient died because of cardiac failure in the fourth month after operation.

Persistent complete heart block was observed in 3 of the patients who recovered. In one, sinus rhythm was spontaneously restored on the 12 th day after the operation: up to then she had an artificial rhythm produced by electrostimulation. Two others still have complete heart block. In one, the electrostimulation was continued for 23 days, and in the other for 17 days. At present all the patients feel well in spite of having complete heart block, and we have not observed any symptoms of cardiac insufficiency.

Eleven patients were examined later, at from 6 months to 3 years. The results in 6 of them after the correction of the incomplete form of the defect can be considered good, and they now have no shunt at all. The pulmonary picture became normal, the heart size significantly decreased (Fig. 10), and the signs of overcharge of the right side of the heart

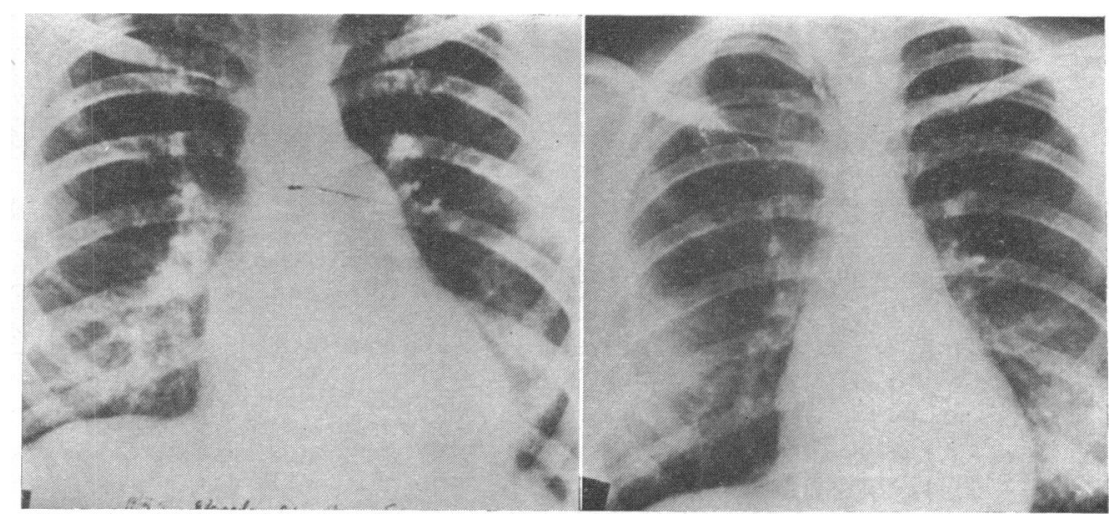

FIG. 10.-Radiographs of a patient before, and 1 year after, the operation for the incomplete form of the cardiac defect. 
disappeared. In only a few patients could the slight systolic murmur at the cardiac apex be heard, perhaps because of cicatricial deformation of the mitral valve. There were no symptoms of mitral regurgitation.

The results obtained by correcting the complete form of the defect were not nearly so good. Even when the operation resulted in some improvement in the condition of the patients, there were still generally rather clearly pronounced circulatory disturbances, basically due to mitral regurgitation. The intensity of the systolic murmur at the apex still remained to a considerable extent. The signs of overcharge of the left side of the heart were clearly seen during the radiological examination.

The improvements in the circulation were noted in the radiographs six months after correction of the complete form of the common A-V canal. A pronounced systolic murmur was still heard at the cardiac apex of these patients, but the pressure in the right ventricle decreased from 60 to $30 \mathrm{~mm}$. $\mathrm{Hg}$, and the left-to-right shunt was abolished.

\section{CONCLUSION}

We have studied and operated on 21 patients with a common atrio-ventricular canal. The investigations showed the diversity of forms of the cardiac defect, especially among patients with the complete type.

Hæmodynamic disorders were serious in all the patients, and included the shunting of blood from the left to the right atrium and from the left ventricle to the right side of the heart, and, in addition, mitral regurgitation. These disorders were particularly serious in the patients with either (a) a common A-V canal with clear halves of the septal cusps of the mitral and tricuspid valves, with a large ventricular septal defect, and a primary atrial septal defect, or (b), a common $\mathrm{A}-\mathrm{V}$ canal without any interatrial septum.

The clinical and radiological picture of the cardiac defect as well as the cardiographic data are pathognomonic.

It is best to operate on the contracting heart with an artificial blood circulation at normal body temperature. The operation for the patients with the incomplete form consists in repair of the split cusps of the mitral valve and in closing the primary atrial septal defect with a teflon patch. In those with a common $A-V$ canal with well-developed ventral and dorsal parts of the septal cusps connected at their lower surface with the edge of the interventricular septum, the ventricular septal defect should be closed with the help of the stitch suggested by Johansson and Senning (1959). In the anatomical varieties (a) and (b) (above) the ventricular septal defect should be closed with a separate patch.

The later results in cases with the incomplete form of cardiac defect are good, the patients becoming normal healthy people. In those with the complete form of the defect the results are not so good because we have been unable to cure the mitral regurgitation.

For a number of patients in the last group we still have to search for new methods of closing the ventricular septal defect and correcting the mitral regurgitation.

\section{REFERENCES}

Amosov, N. M., Lissov, J. L., Sidarenko, L. N., and Treshinski, A. M. (1962). Cardiac operations using artificial blood circulation. Medgiz, Kiev.

Bourakovski, V. I., Bukharin, V. A., Romashov, F. N., and Su-Chzhun, Huan (1963). Classification, clinics, diagnostics and surgical treatment of the complete form of the atrio-ventricular canal. Vestnik Academy of Medical Science, U.S.S.R., 9, 32.

-, and Romashov, F. N. (1962). Indications for the operation and choosing the methods in cases with the interatrial septal defect. Chest surgery, No. 1, 3.

Johansson, L., and Senning, Å. (1959). Surgical correction of atrial septal defects. Acta chir. scand., Suppl. 245, p. 283.

Kolesnikov, S. A. (1961). Operations on the open heart under conditions of artificial blood circulation. Reports of the Chest Surgery Institute, VII. Medgiz, Kiev.

Kuprianov, P. A. (1962). The blood circulation in surgical treatment of the heart and main vessels. Medgiz, Kiev.

Lillehei, C. W., Warden, H. E., DeWall, R. A., Stanley, P., and Varco, R. L. (1957). Cardiopulmonary by-pass in surgical treatment of congenital or acquired cardiac disease. Use in 305 patients. Arch. Surg., 75, 928.

McGoon, D. C., DuShane, J. W., and Kirklin, J. W. (1959). The surgical treatment of endocardial cushion defects. Surgery, 46, 185.

Petrovski, B. V., Soloviev, G. M., Bunatin, A. A., Chodas, M. J., Osipov, V. P., Zargarli, F. I., and Shumakov, V. I. (1962). Hypothermal perfusion during the operations on the open heart. Report at the conference of the cardiovascular surgery link, Moscow, December 1962.

Romashov, F. N. (1963). Defects of interatrial septum and their surgical treatment. Khirurgiya (Mosk.), 39, No. 2, p. 70. [In Russian-Eng. Summary.]

Scott, L. P., Hauck, A. J., Nadas, A. S., and Gross, R. E. (1962). Endocardial cushion defect. Preoperative and postoperative survey. Circulation, 26, 218.

Vishnevski, A. A., and Galankin, N. K. (1962). Congenital cardiac defects and defects of big vessels. Medgiz, Kiev.

Wakai, C. S., and Edwards, J. E. (1956). Developmental and pathologic considerations in persistent common atrioventricular canal. Proc. Mayo Clin., 31, 487. 